\title{
Cross resistance analysis of Cercospora beticola to triazole (DMI) fungicides
}

\section{Analiza odporności krzyżowej Cercospora beticola na fungicydy triazolowe (DMI)}

\author{
Katarzyna Pieczul ${ }^{1 *}$, Agnieszka Łacka ${ }^{2}$
}

\section{Summary}

The results of the growth inhibition level of isolates culturing on PDA (Potato Dextrose Agar) medium containing prochloraz, cyproconazole, epoxiconazole, flusilazole, tebuconazole and tetraconazole at various concentrations were used in the studies of Cercospora beticola cross resistance to triazole (demethylation inhibitors - DMI) fungicides. Spearman correlation matrix was determined for all active substances and illustrated by heat maps, and followed by cluster analysis. Between the ranks of correlation coefficients of the individual active substances a trend emerged indicating the similarity between some of them and, associated with the risk of resistance development. The greatest risk of cross resistance forming was identified for the following groups: cyproconazole and tetraconazole; tebuconazole, flusilazole and epoxiconazole. The statistical analysis indicated also the possibility of using prochloraz for control of $C$. beticola strains with decreasing sensitivity or resistant to triazoles.

Key words: cross resistance; Cercospora beticola; triazole

\section{Streszczenie}

W badaniach odporności krzyżowej izolatów Cercospora beticola na fungicydy triazolowe (demethylation inhibitors - DMI) wykorzystano wyniki analiz stopnia hamowania wzrostu izolatów rosnących na pożywce PDA (Potato Dextrose Agar) przez dodane do podłoża w różnych stężeniach: prochloraz, cyprokonazol, epoksykonazol, flusilazol, tebukonazol i tetrakonazol. Dla wszystkich badanych substancji czynnych wyznaczono macierz korelacji rang Spearmana, którą zilustrowano przy pomocy map ciepła, a następnie przeprowadzono analizę skupień. Pomiędzy wartościami współczynników korelacji poszczególnych substancji czynnych zarysowały się tendencje do grupowania, wskazujące na podobieństwa między niektórymi z nich związane z ryzykiem powstawania odporności na triazole. Największe ryzyko powstawania odporności krzyżowej zidentyfikowano dla grup: cyprokonazol i tetrakonazol oraz tebukonazol, flusilazol i epoksykonazol. Analiza statystyczna wskazała jednocześnie na możliwość wykorzystania prochlorazu w zwalczaniu szczepów C. beticola o obniżonej wrażliwości lub odpornych na triazole.

Słowa kluczowe: odporność krzyżowa; Cercospora beticola; triazole

\footnotetext{
$\overline{1}$ Instytut Ochrony Roślin - Państwowy Instytut Badawczy Zakład Mikologii

Władysława Węgorka 20, 60-318 Poznań

${ }^{2}$ Uniwersytet Przyrodniczy w Poznaniu

Katedra Metod Matematycznych i Statystycznych

Wojska Polskiego 28, 60-637 Poznań

*corresponding author: k.pieczul@iorpib.poznan.pl
} 


\section{Wstęp / Introduction}

Chwościk buraka wywoływany przez Cercospora beticola jest jedną $\mathrm{z}$ najważniejszych chorób buraka cukrowego, występujących w Polsce corocznie. Na szybki rozwój i rozprzestrzenianie choroby wpływają m.in.: dostępność inokulum patogena, wysokie temperatury oraz częste opady deszczu sprzyjające rozprzestrzenianiu zarodników konidialnych. W ograniczeniu występowania chwościka ważną rolę odgrywa dobór odmian o podwyższonej odporności, prawidłowe wykonywanie zabiegów agrotechnicznych oraz stosowanie fungicydów (Wolf i Verreet 2002). Podstawowymi fungicydami stosowanymi w Polsce do ochrony buraka cukrowego przed tą chorobą sa triazole, głównie epoksykonazol, tebukonazol i tetrakonazol (Zalecenia Ochrony Roślin 2014/2015).

Triazole (demethylation inhibitors - DMI) są liczną grupą systemicznych fungicydów, wprowadzoną do stosowania w ochronie roślin w latach 70 . XX wieku. Ich działanie polega na specyficznym wiązaniu z $14 \alpha$-dimetylazą sterolu, enzymem uczestniczącym w syntezie ergosterolu. Skutkiem zahamowania prawidłowego funkcjonowania enzymu jest gromadzenie intermediatów ergosterolu, prowadzących do zmian funkcjonowania i struktury błony komórkowej (Lepesheva i Waterman 2007). Triazole należą do fungicydów, na które grzyby uodporniają się średnio szybko. Stopniowy spadek wrażliwości izolatów $C$. beticola na triazole jest obserwowany w Europie od połowy lat 90. XX wieku, w Polsce około 10 lat później (Karaoglanidis i wsp. 2000; Karaoglanidis i Thanassoulopoulos 2003; Piszczek 2010). Na podstawie badań laboratoryjnych szacuje się, że w roku 2012 liczba izolatów C. beticola o obniżonej wrażliwości na triazole w zależności od stosowanej substancji czynnej oraz miejsca pochodzenia wynosiła od 0 do $30 \%$ (Pieczul i Perek 2013). Wcześniejsze badania, prowadzone w latach 2004-2008 na terenie centralnej Polski wskazują, że częstość występowania izolatów o obniżonej wrażliwości na triazole była podobna i wynosiła od 0 do $32 \%$ (Piszczek 2010).

Odporność patogenów na fungicydy $\mathrm{z}$ grupy triazoli zazwyczaj spowodowana jest mutacjami w genie $14 \alpha$-dimetylazy sterolu (cyp51). Dotychczas opisanych zostało kilkanaście mutacji odpowiadających za to zjawisko u różnych gatunków grzybów (Wynard i Brown 2005; Cools i wsp. 2011), lecz nie u C. beticola. Inną przyczyną spadku wrażliwości grzybów na triazole może być wzrost ekspresji genu cyp51 lub białek transportowych, usuwających fungicydy $\mathrm{z}$ wnętrza komórek (Ma i Michailides 2005; Nikou i wsp. 2009; Bolton i wsp. 2013). U izolatów grzybów, które nabyły odporność na substancje czynne z grupy triazoli często obserwowane jest zjawisko odporności krzyżowej. Polega ono na jednoczesnym wykształceniu odporności na szereg substancji czynnych o takim samym mechanizmie działania grzybobójczego. Odporność krzyżowa w obrębie grupy DMI obserwowana u patogenów, każdorazowo stanowi poważną przeszkodę w zastępowaniu jednych fungicydów triazolowych innymi (Cunha i Rizzo 2003; Karaoglanidis i Thanassoulopoulos 2003; Faria-Ramos i wsp. 2014).
Celem badań była ocena ryzyka powstawania odporności krzyżowej u izolatów $C$. beticola na różne substancje czynne z grupy triazoli.

\section{Materiały i metody / Materials and methods}

\section{Badania laboratoryjne}

Izolaty $C$. beticola (55 izolatów) uzyskano z naturalnie porażonych liści buraka cukrowego, zbieranych na terenie Wielkopolski w 2013 roku. Izolacji kultur grzybów dokonywano według metodyki opisanej przez Pieczul i Perek (2013).

Przeprowadzone badania laboratoryjne polegały na ocenie hamowania wzrostu liniowego izolatów przez czyste substancje czynne (Sigma): prochloraz (imidazol), epoksykonazol, cyprokonazol, flusilazol, tebukonazol, tetrakonazol (triazole) dodane do pożywki PDA (Potato Dextrose Agar, Difco) w stężeniach 1, 3 i 10 ppm. Substancje czynne przed dodaniem do pożywki zostały rozpuszczone w metanolu, w stężeniu $5 \mathrm{mg} / \mathrm{ml}$. Kontrolę stanowiły kolonie rosnące na pożywce PDA bez dodatku fungicydu. Na pożywki z określoną zawartością substancji czynnej zaszczepiano niewielki fragment pobrany z dwutygodniowej grzybni rosnącej na pożywce PDA. Po 7 dniach inkubacji w temperaturze pokojowej mierzono wzrost liniowy wszystkich izolatów i przeliczano w stosunku do wzrostu kultury kontrolnej, oznaczając w skali 0-4, wyrażającej stosunek wielkości wzrostu kolonii rosnącej na podłożu z substancją czynną do kolonii kontrolnej rosnącej na pożywce PDA bez fungicydu. W badaniach przyjęto następujące oznaczenia: 0 - izolaty bardzo wrażliwe, brak wzrostu, 1 - wrażliwe (1-20\% wzrostu w stosunku do średnicy kolonii kontrolnej), 2 średniowrażliwe $(20-50 \%), 3$ - odporne $(50-80 \%), 4$ całkowicie odporne $(>80 \%)$. Badanie zostało wykonane dwukrotnie.

Do analizy statystycznej dołączono wyniki badań hamowania wzrostu liniowego przez substancje czynne z grupy triazoli 185 izolatów zbieranych w roku 2012 na terenie województwa wielkopolskiego (Pieczul i Perek 2013). Podsumowanie wyników badań laboratoryjnych jako średnie odporności dla 240 izolatów (z lat 2012-2013) na poszczególne substancje czynne przedstawione zostało w tabeli 5 .

\section{Analiza statystyczna}

Dla substancji czynnych w poszczególnych stężeniach (1, 3 i $10 \mathrm{ppm}$ ) oraz dla substancji bez podziału na stężenia wyznaczono macierz korelacji rang Spearmana, którą zilustrowano przy pomocy map ciepła. W kolejnym kroku analizy przeprowadzono analizę skupień (cluster analysis), której celem było ułożenie badanych kombinacji w grupy w taki sposób, aby stopień powiązania ich w obrębie tej samej grupy był jak największy, a z kombinacjami $z$ innych grup jak najmniejszy. Stosując miarę odległości euklidesowej uzyskano diagram drzewa. Na tej podstawie można stwierdzić, że struktura podobieństwa oddziaływania poszczególnych substancji czynnych na zahamowania wzrostu izolatów jest podobna mniej lub bardziej 
W zależności od obranej wartości odległości euklidesowej. Analiza została wykonana w programie R 3.2.2.

\section{Wyniki i dyskusja / Results and discussion}

Triazole oraz prochloraz należą do substancji skutecznie ograniczających wzrost liniowy izolatów $C$. beticola (tab. 5). Wśród izolatów zbieranych w latach 2012-2013 zidentyfikowane zostały jednak szczepy charakteryzujące się obniżoną wrażliwością na triazole oraz prochloraz dodane do pożywki w stężeniach 1,3 , a nawet 10 ppm. W zależności od stężenia i rodzaju substancji czynnej liczba izolatów odpornych wynosiła od 0 do $30 \%$. Większość z ww. izolatów charakteryzowała się jednoczesnym spadkiem wrażliwości na różne substancje z grupy triazoli.

$\mathrm{Na}$ podstawie analiz statystycznych przedstawionych w niniejszej pracy stwierdzono, że między wartościami współczynników korelacji wyrażającymi stopień hamowania wzrostu izolatów przez poszczególne substancje czynne zarysowały się tendencje do grupowania, mogące wskazywać na ryzyko powstawania odporności krzyżowej u izolatów $C$. beticola na fungicydy triazolowe. Tendencje te podlegały niewielkim zmianom, w zależności od zastosowanego stężenia badanych substancji czynnych. W przypadku stężeń 1 oraz 3 ppm, stwierdzono podobieństwo W strukturze skupień. W obu przypadkach, przyjmując odległość 0,65 wyodrębnione zostały trzy główne skupienia (tab. 1, 2, rys. 1, 2). Do pierwszego skupienia należał jedynie prochloraz - substancja słabo skorelowana z pozostałymi związkami pod względem stopnia hamowania wzrostu izolatów. Do drugiej grupy zaliczono tetrakonazol i cyprokonazol, a korelacje między tymi związkami uksz- tałtowały się na poziomie $0,83 \mathrm{w}$ przypadku stężenia 1 ppm i 0,68 dla stężenia 3 ppm. Skupienie trzecie wykazywało charakter wstępujący. Najmniejszą odległością w obrębie tego skupienia charakteryzował się flusilazol i tebukonazol, dla których współczynnik korelacji wynosił 0,76 w przypadku stężenia 1 ppm i 0,75 dla stężenia 3 ppm. Ostatnim obiektem należącym do tego skupienia był epoksykonazol, skorelowany zarówno z flusilazolem (współczynnik korelacji 0,75 dla stężenia 1 ppm i 0,63 dla $3 \mathrm{ppm}$ ), jak i z tebukonazolem (odpowiednio 0,63 i 0,59 dla 1 i 3 ppm) pod względem stopnia hamowania wzrostu izolatów. Analiza statystyczna wyników badań wykonana dla stężenia 10 ppm zmieniła sposób grupowania substancji czynnych, wskazując na największe podobieństwo współczynników korelacji między cyprokonazolem i flusilazolem (tab. 3, rys. 3). Współczynnik korelacji tych substancji dla stopnia hamowania wzrostu izolatów wyniósł 0,70. Zbiorcza analiza wyników (bez podziału na stężenia) wskazała ponownie na największe prawdopodobieństwo powstawania odporności krzyżowej w grupach: cyprokonazol i tetrakonazol oraz tebukonazol, flusilazol i epoksykonazol (tab. 4, rys. 4).

Zjawisko odporności krzyżowej izolatów $C$. beticola na fungicydy triazolowe, ale także inne grupy fungicydów obserwowane było przez Karaoglanidisa i Thanassoulopulosa (2003). Na podstawie uzyskanych wyników ww. autorzy wskazali korzystne lub niekorzystne połączenia fungicydów stosowanych $\mathrm{w}$ ochronie buraka cukrowego. Także wyniki uzyskane $\mathrm{w}$ niniejszej pracy pozwalają wskazać mniej lub bardziej korzystne połączenia fungicydów. Przykładem może być unikanie ciągłego stosowania preparatów posiadających w swoim składzie tebukonazol i epoksykonazol, przez zastąpienie jednego $\mathrm{z}$ nich tetrakonazolem lub substancją czynną z innej grupy

Tabela 1. Macierz korelacji dla stopnia hamowania wzrostu izolatów przy stężeniu $1 \mathrm{ppm}$

Table 1. Correlation matrix for the degree of growth inhibition of isolates at the concentration of $1 \mathrm{ppm}$

\begin{tabular}{l|c|c|c|c|c|c}
\hline $\begin{array}{c}\text { Substancja czynna } \\
\text { Active substance }\end{array}$ & Prochloraz & Cyproconazole & Epoxiconazole & Flusilazole & Tebuconazole & Tetraconazole \\
\hline Prochloraz & 1,000 & 0,474 & 0,339 & 0,316 & 0,331 & 0,430 \\
Cyproconazole & 0,474 & 1,000 & 0,647 & 0,647 & 0,678 & 0,827 \\
Epoxiconazole & 0,339 & 0,647 & 1,000 & 0,753 & 0,721 & 0,663 \\
Flusilazole & 0,316 & 0,647 & 0,753 & 1,000 & 0,756 & 0,620 \\
Tebuconazole & 0,331 & 0,678 & 0,721 & 0,756 & 1,000 & 0,667 \\
Tetraconazole & 0,430 & 0,827 & 0,663 & 0,620 & 0,667 & 1,000 \\
\hline
\end{tabular}

Tabela 2. Macierz korelacji dla stopnia hamowania wzrostu izolatów przy stężeniu 3 ppm

Table 2. Correlation matrix for the degree of growth inhibition of isolates at the concentration of $3 \mathrm{ppm}$

\begin{tabular}{l|c|c|c|c|c|c}
\hline $\begin{array}{c}\text { Substancja czynna } \\
\text { Active substance }\end{array}$ & Prochloraz & Cyproconazole & Epoxiconazole & Flusilazole & Tebuconazole & Tetraconazole \\
\hline Prochloraz & 1,000 & 0,277 & 0,270 & 0,369 & 0,406 & 0,356 \\
Cyproconazole & 0,277 & 1,000 & 0,569 & 0,575 & 0,510 & 0,682 \\
Epoxiconazole & 0,270 & 0,569 & 1,000 & 0,633 & 0,592 & 0,628 \\
Flusilazole & 0,369 & 0,575 & 0,633 & 1,000 & 0,750 & 0,675 \\
Tebuconazole & 0,406 & 0,510 & 0,592 & 0,750 & 1,000 & 0,675 \\
Tetraconazole & 0,356 & 0,682 & 0,628 & 0,675 & 0,675 & 1,000 \\
\hline
\end{tabular}


Tabela 3. Macierz korelacji dla stopnia hamowania wzrostu izolatów przy stężeniu 10 ppm

Table 3. Correlation matrix for the degree of growth inhibition of isolates at the concentration of $10 \mathrm{ppm}$

\begin{tabular}{l|c|c|c|c|c|c}
\hline $\begin{array}{c}\text { Substancja czynna } \\
\text { Active substance }\end{array}$ & Prochloraz & Cyproconazole & Epoxiconazole & Flusilazole & Tebuconazole & Tetraconazole \\
\hline Prochloraz & 1,000 & 0,254 & 0,181 & 0,196 & 0,281 & 0,259 \\
Cyproconazole & 0,254 & 1,000 & 0,599 & 0,698 & 0,595 & 0,682 \\
Epoxiconazole & 0,181 & 0,599 & 1,000 & 0,667 & 0,569 & 0,548 \\
Flusilazole & 0,196 & 0,698 & 0,667 & 1,000 & 0,693 & 0,651 \\
Tebuconazole & 0,281 & 0,595 & 0,569 & 0,693 & 1,000 & 0,631 \\
Tetraconazole & 0,259 & 0,682 & 0,548 & 0,651 & 0,631 & 1,000 \\
\hline
\end{tabular}

Tabela 4. Macierz korelacji dla stopnia hamowania wzrostu izolatów bez podziału na stężenia

Table 4. Correlation matrix for the degree of growth inhibition of isolates without the concentration substances

\begin{tabular}{l|c|c|c|c|c|c}
\hline $\begin{array}{c}\text { Substancja czynna } \\
\text { Active substance }\end{array}$ & Prochloraz & Cyproconazole & Epoxiconazole & Flusilazole & Tebuconazole & Tetraconazole \\
\hline Prochloraz & 1,000 & 0,410 & 0,345 & 0,386 & 0,415 & 0,415 \\
Cyproconazole & 0,410 & 1,000 & 0,698 & 0,727 & 0,684 & 0,804 \\
Epoxiconazole & 0,345 & 0,698 & 1,000 & 0,751 & 0,707 & 0,688 \\
Flusilazole & 0,386 & 0,727 & 0,751 & 1,000 & 0,793 & 0,718 \\
Tebuconazole & 0,415 & 0,684 & 0,707 & 0,793 & 1,000 & 0,715 \\
Tetraconazole & 0,415 & 0,804 & 0,688 & 0,718 & 0,715 & 1,000 \\
\hline
\end{tabular}

Tabela 5. Średnie stopnie hamowania wzrostu izolatów Cercospora beticola zbieranych w latach 2012-2013 przez substancje czynne

Table 5. The mean growth inhibition level of Cercospora beticola isolates collected in 2012-2013 by active substances

\begin{tabular}{l|c|c|c}
\hline \multirow{2}{*}{$\begin{array}{c}\text { Substancja czynna } \\
\text { Active substance }\end{array}$} & \multicolumn{3}{|c}{ Stężenie w ppm - Concentration in ppm } \\
\cline { 2 - 4 } \multicolumn{1}{c|}{} & 1,50 & 3 & 10 \\
\hline Prochloraz & 1,96 & 1,28 & 0,00 \\
Cyproconazole & 1,42 & 1,15 & 0,59 \\
Epoxiconazole & 1,54 & 0,85 & 0,42 \\
Flusilazole & 1,67 & 0,95 & 0,44 \\
Tebuconazole & 1,50 & 1,20 & 0,60 \\
Tetraconazole & 1,03 & 0,54 \\
\hline
\end{tabular}

Najniższe wartości liczbowe wskazują na najwyższą skuteczność ograniczania wzrostu izolatów (w skali 0-4)

The lowest numbers indicate the highest effectiveness of control of the growth of isolates (in the $0-4$ scale)
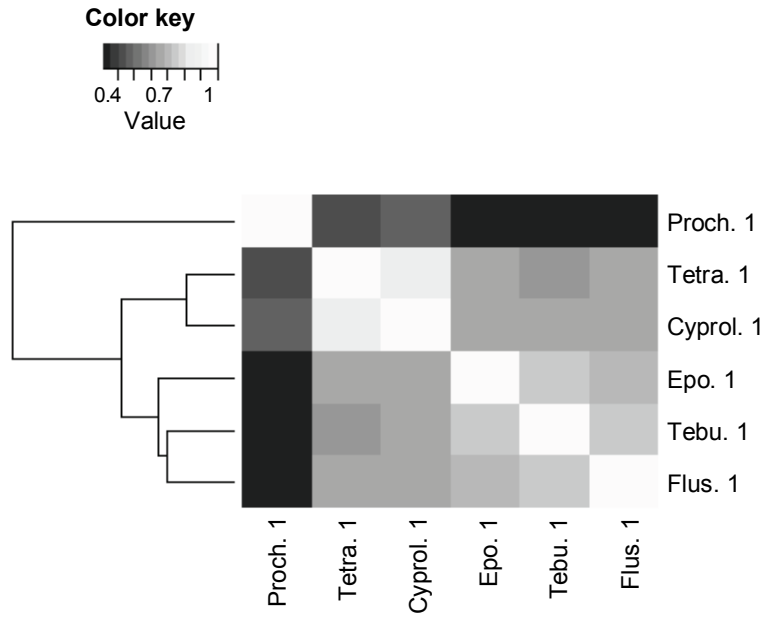

Rys. 1. Mapa ciepła dla wartości współczynników korelacji rang Spearmana dla stopnia hamowania wzrostu izolatów przy stężeniu $1 \mathrm{ppm}$ oraz odpowiedni diagram drzewa

Fig. 1. Heat map for Spearman's rank correlation coefficients for the degree of growth inhibition isolates at a concentration of $1 \mathrm{ppm}$ and the appropriate tree diagram
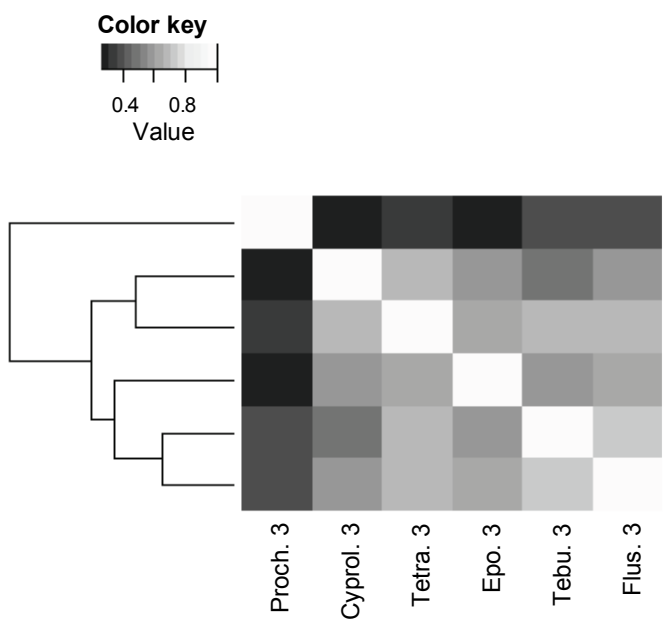

Proch. 3

Cyprol. 3

Tetra. 3

Epo. 3

Tebu. 3

Flus. 3

Rys. 2. Mapa ciepła dla wartości współczynników korelacji rang Spearmana dla stopnia hamowania wzrostu izolatów przy stężeniu 3 ppm oraz odpowiedni diagram drzewa

Fig. 2. Heat map for Spearman's rank correlation coefficients for the degree of growth inhibition isolates at a concentration of $3 \mathrm{ppm}$ and the appropriate tree diagram 


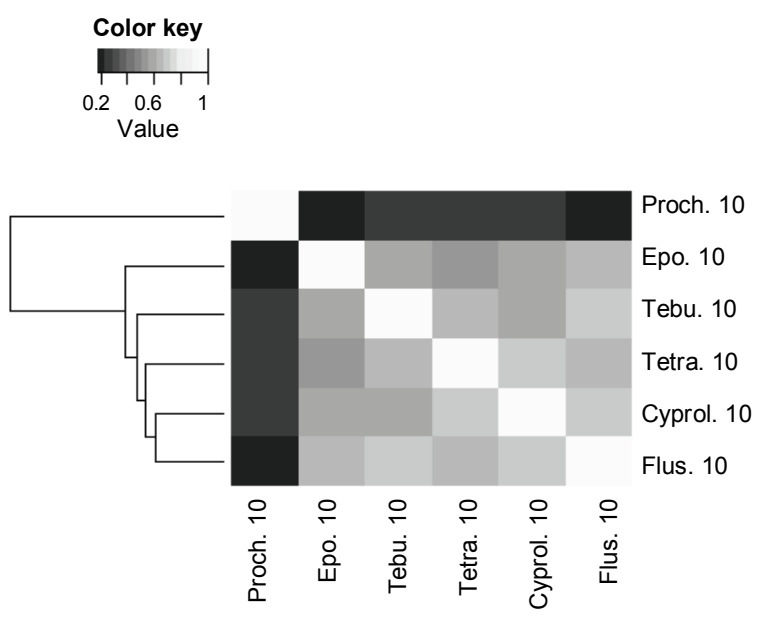

Rys. 3. Mapa ciepła dla wartości współczynników korelacji rang Spearmana dla stopnia hamowania wzrostu izolatów przy stężeniu $10 \mathrm{ppm}$ oraz odpowiedni diagram drzewa

Fig. 3. Heat map for Spearman's rank correlation coefficients for the degree of growth inhibition isolates at a concentration of $10 \mathrm{ppm}$ and the appropriate tree diagram

chemicznej (np. fenpropimorf, piraklostrobina). Analiza statystyczna wskazała jednocześnie możliwość wykorzystania prochlorazu w zwalczaniu szczepów $C$. beticola o obniżonej wrażliwości lub odpornych na triazole. Prochloraz wykazywał najniższe wartości współczynników korelacji we wszystkich rozważanych stężeniach (tab. 1-4, rys. 1-4). Zjawisko to może świadczyć o zaangażowaniu innych mechanizmów w nabywanie odporności na prochloraz i triazole. Prochloraz według Zaleceń Ochrony Roślin (2014/2015) nie znajdował się na liście preparatów zarejestrowanych do zwalczania chwościka buraka.

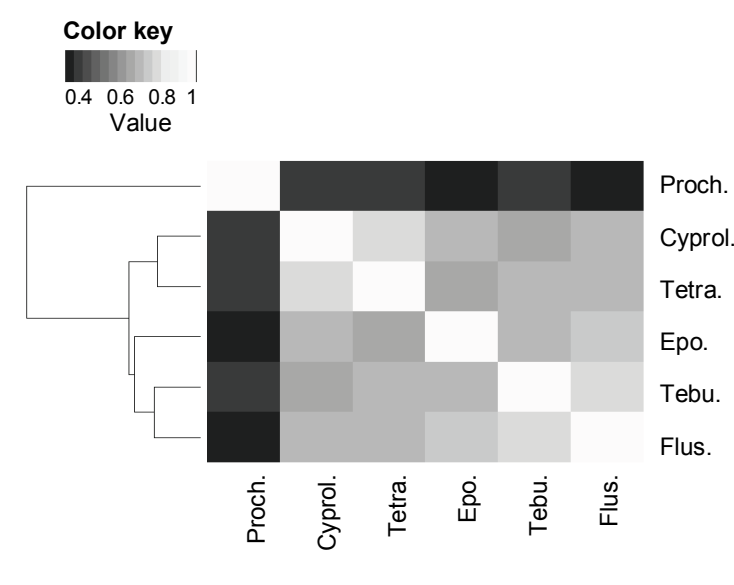

Rys. 4. Mapa ciepła dla wartości współczynników korelacji rang Spearmana dla stopnia hamowania wzrostu izolatów bez podziału na stężnia oraz odpowiedni diagram drzewa

Fig. 4. Heat map for Spearman's rank correlation coefficients for the degree of growth inhibition isolates without the segregation by concentration and the appropriate tree diagram

\section{Wnioski / Conclusions}

1. Między wartościami współczynników korelacji dla poszczególnych substancji czynnych zarysowały się tendencje do grupowania, mogące wskazywać na ryzyko powstawania odporności krzyżowej na triazole (grupy: tetrakonazol i cyprokonazol oraz tebukonazol, epoksykonazol i flusilazol) wśród izolatów C. beticola.

2. Prochloraz wykazywał najniższe wartości współczynników korelacji z substancjami czynnymi z grupy triazoli, co wskazuje na możliwości wykorzystania tej substancji w zwalczaniu szczepów $C$. beticola o obniżonej wrażliwości lub odpornych na triazole.

\section{Literatura / References}

Bolton M.D., Riviera V., Secor G. 2013. Identification of the G143A mutation associated with Qol resistance in Cercospora beticola field isolates from Michigan, United States. Pest Management Science 69: 35-39.

Cools H.J., Mullins G.L., Fraaije B.A., Parker J.E., Kelly D.E., Lucas J.A., Kelly S.L. 2011. Impact in recently emerged sterol 14-demethylase (CYP51) variants of Mycosphaerella graminicola on azole fungicide sensitivity. Applied and Environmental Microbiology 77: 3830-3837.

Cunha M.G., Rizzo D.M. 2003. Development of fungicide cross resistance in Helminthosporium solani populations from California. Plant Disease 87: 798-803.

Faria-Ramos I., Farinha S., Neves-Maia J., Tavares P.R., Miranda I.M., Estevinho L.M., Pina-Vaz C., Rodriguez A.G. 2014. Development of cross-resistance by Aspergillus fumigatus to clinical azoles following exposure to prochloraz, an agricultural azole. BMC Microbiology 14, p. 155. DOI: 10.1186/1471-2180-14-155.

Karaoglanidis G.S., Ioannidis P.M., Thanassoulopoulos C.C. 2000. Reduced sensitivity of Cercospora beticola isolates to steroldemethylation-inhibiting fungicides. Plant Pathology 49 (5): 567-572.

Karaoglanidis G.S., Thanassoulopoulos C.C. 2003. Cross-resistance patterns among sterol biosynthesis inhibiting fungicides (SBIs) in Cercospora beticola. European Journal of Plant Pathology 109 (9): 929-934.

Lepesheva G.I., Waterman M.R. 2007. Sterol 14-demethylase cytochrome P450 (Cyp51), a P450 in all biological kingdoms. Biochemica et Biophysica Acta 1770 (3): 467-477.

Ma Z., Michailides T.J. 2005. Advances in understanding molecular mechanism of fungicide resistance and molecular detection of resistant genotypes in phytopathogenic fungi. Crop Protection 24 (10): 853-863. 
Nikou D., Malandrakis A., Konstantakaki M., Vontas J., Markoglou A., Ziogas B. 2009. Molecular characterization and detection of overexpressed C-14 alpha-demethylase-based DMI resistance in Cercospora beticola field isolates. Pesticide Biochemistry and Physiology 95 (1): 18-27.

Pieczul K., Perek A. 2013. Odporność na fungicydy izolatów Cercospora beticola pochodzących z terenu Wielkopolski. [Fungicide resistance of Cercospora beticola isolates collected from Wielkopolska region]. Progress in Plant Protection/Postępy w Ochronie Roślin 53 (4): 796-800.

Piszczek J. 2010. Epidemiologia chwościka buraka cukrowego (Cercospora beticola) w Centralnej Polsce. Rozprawy Naukowe Instytutu Ochrony Roślin - Państwowego Instytutu Badawczego 23, 70 ss.

Wolf P.F.J., Verreet J.A. 2002. An integrated pest management system in Germany for the control of fungal leaf diseases in sugar beet: the IPM sugar beet model. Plant Disease 86: 336-344.

Wynard R.A., Brown J.K.M. 2005. Sequence variation in the Cyp51 gene of Blumeria graminis associated with resistance to sterol demethylase inhibiting fungicides. Fungal Genetics and Biology 42: 726-735.

Zalecenia Ochrony Roślin na lata 2014/2015. Cz. I, Rośliny Rolnicze. 2015. Instytut Ochrony Roślin - PIB, Poznań, 327 ss. 